\title{
HDliveFlow Silhouette Mode with HDlive Silhouette Mode for Diagnosis of Sclerosing Stromal Tumor of the Ovary
}

\author{
${ }^{1}$ Chiaki Tenkumo, ${ }^{2}$ Uiko Hanaoka, ${ }^{3}$ Kenji Kanenishi, ${ }^{4}$ Tamaki Tanaka, ${ }^{5}$ Yuko Fukuda, ${ }^{6}$ Toshiyuki Hata
}

\begin{abstract}
We present our experience of using the HDliveFlow silhouette mode with HDlive silhouette mode to diagnose sclerosing stromal tumor (SST) of the ovary. Two-dimensional (2D) sonography showed an echogenic solid tumor with some anechoic areas inside the mass. Two-dimensional power Doppler depicted peripheral vascularity with a few central vessels inside the mass. HDliveFlow clearly showed abundant peripheral vascularization with several penetrating vessels (scrubbing-brush appearance). The HDliveFlow silhouette mode with HDlive silhouette mode revealed numerous peripheral vessels with some penetrating vessels and a few cysts inside the mass. Magnetic resonance imaging (MRI) was highly suggestive of SST. Laparoscopic right salpingo-oophorectomy was performed, and the histopathologic diagnosis was SST of the right ovary. The HDliveFlow silhouette mode with HDlive silhouette mode may facilitate the preoperative diagnosis of SST as an additional diagnostic tool along with conventional 2D power Doppler sonography.
\end{abstract}

Keywords: HDlive silhouette mode, HDliveFlow silhouette mode, Laparoscopic surgery, Ovary, Sclerosing stromal tumor.

How to cite this article: Tenkumo C, Hanaoka U, Kanenishi K, Tanaka T, Fukuda Y, Hata T. HDliveFlow Silhouette Mode with HDlive Silhouette Mode for Diagnosis of Sclerosing Stromal Tumor of the Ovary. Donald School J Ultrasound Obstet Gynecol 2018;12(2):85-88.

Source of support: Nil

Conflict of interest: None

\section{INTRODUCTION}

Sclerosing stromal tumor is a rare benign solid tumor of the ovary that is classified as a sex cord stromal tumor. ${ }^{1}$ It often occurs in young woman, causing menstrual irregularity, abdominal discomfort, and ascites retention..$^{2-4}$ As SSTs are rare ovarian tumors, preoperative diagnosis is

\footnotetext{
${ }^{1,4}$ Assistant Professor, ${ }^{2,5}$ Lecturer, ${ }^{3}$ Associate Professor ${ }^{6}$ Professor and Chairman

${ }^{1-4,6}$ Department of Perinatology and Gynecology, Kagawa University Graduate School of Medicine, Miki, Kagawa, Japan

${ }^{5}$ Department of Radiology, Kagawa University Graduate School of Medicine, Miki, Kagawa, Japan
}

Corresponding Author: Toshiyuki Hata, Professor and Chairman, Department of Perinatology and Gynecology Kagawa University Graduate School of Medicine, Miki, Kagawa Japan, Phone: +810878912174, e-mail: toshi28@med. kagawa-u.ac.jp difficult. ${ }^{5}$ In view of the possibility of a malignant tumor, there have been many cases of selecting open surgery for SSTs. ${ }^{3}$ However, preoperative differentiation between benign and malignant tumors of the ovary is mandatory for optimizing management.

The HDliveFlow silhouette mode with HDlive silhouette mode comprehensively demonstrates the orientation and localization of the inner structure and blood vessel configuration in fetal heart and gynecologic disorders. ${ }^{6-9}$ To the best of authors' knowledge, there has been no report on the use of the HDliveFlow silhouette mode with HDlive silhouette mode for the diagnosis of SST.

\section{CASE REPORT}

An 18-year-old nulliparous Japanese woman was referred to our university hospital because of a right ovarian solid tumor. She had a history of menstrual irregularity for several months. Although routine laboratory findings were unremarkable, the serum level of cancer antigen $72-4$ was slightly elevated $(23.1 \mathrm{U} / \mathrm{mL})$. Transvaginal 2D sonography (Voluson E8, GE Healthcare Japan, Tokyo, Japan) depicted a solid 40-mm tumor with moderate echogenicity and some anechoic areas inside the mass of the right ovary (Fig. 1A). There was no ascites in the pelvic cavity. Transvaginal 2D power Doppler revealed peripheral vascularity with a few central vessels inside the mass (Fig. 1B). HDliveFlow (Voluson E10, GE Healthcare Japan, Tokyo, Japan) clearly showed abundant peripheral vascularization with several penetrating vessels (scrubbing-brush appearance) (Fig. 2). Moreover, the HDliveFlow silhouette mode with HDlive silhouette mode revealed numerous peripheral vessels with some penetrating vessels and a few cysts inside the mass (Fig. 3). Magnetic resonance imaging revealed that its central portion had the same signal intensity as water and exhibited a high signal intensity on T2-weighted imaging (Fig. 4). The peripheral portion of the tumor was slightly hyperintense relative to muscle. T2-weighted imaging depicted a thin, low-intensity rim surrounding the tumor. Dynamic contrast-enhanced MRI demonstrated marked early enhancement of the peripheral portion of the tumor. A diagnosis of SST of the ovary was strongly suspected, and laparoscopic right salpingo-oophorectomy was performed (Fig. 5). Histopathology confirmed SST of the right ovary. 

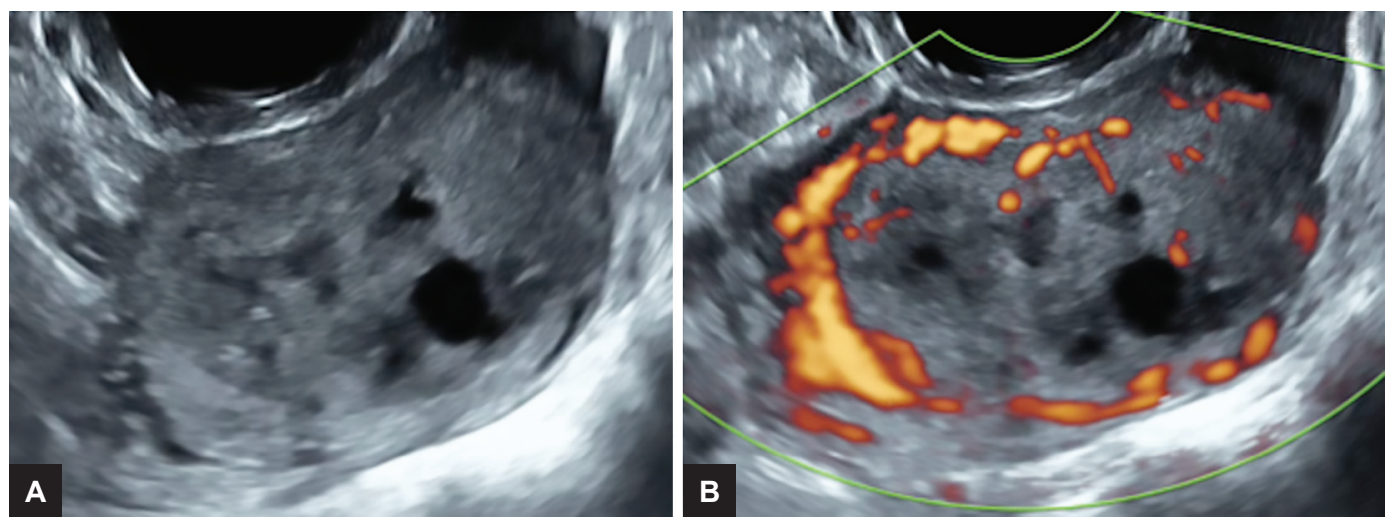

Figs 1A and B: Transvaginal 2D sonographic (A) and power Doppler (B) images of a SST of the right ovary in an 18-year-old Japanese woman. Two-dimensional sonography shows a moderately echogenic tumor with some anechoic areas inside the mass of the right ovary (A). Two-dimensional power Doppler reveals peripheral vascularity with a few central vessels inside the mass $(B)$

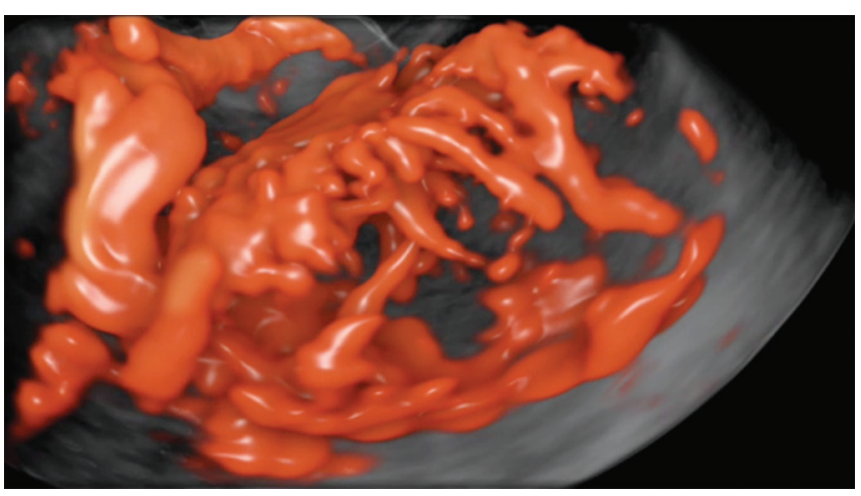

Fig. 2: HDliveFlow image of a SST of the right ovary. Abundant peripheral vascularization with several penetrating vessels (scrubbing-brush appearance) can be noted

\section{DISCUSSION}

On 2D sonography, SSTs are solid cyst with multiple round or cleft-like cysts. ${ }^{10}$ Moreover, on 2D color Doppler, SSTs are very hypervascular in peripheral solid areas

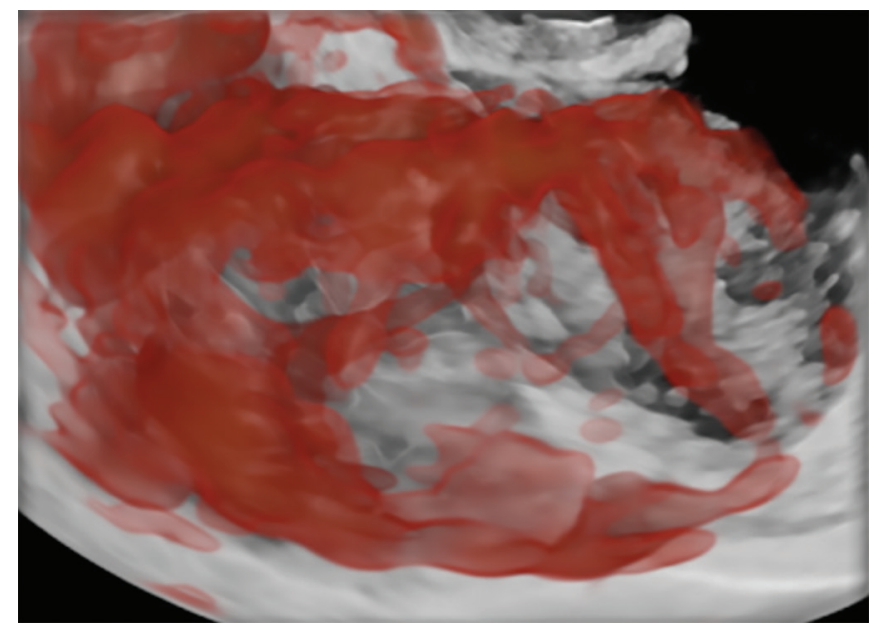

Fig. 3: HDliveFlow silhouette mode with HDlive silhouette mode images of a SST of the right ovary. The HDliveFlow silhouette mode with HDlive silhouette mode clearly reveals numerous peripheral vessels with some penetrating vessels and a few cysts inside the mass and internal intercystic spaces. ${ }^{10}$ Deval et al ${ }^{11}$ reported that the "association of an echogenic ovarian mass with acoustic shadowing and a high degree of peripheral vascularization may strongly suggest the diagnosis of SST of the ovary." In the present case, transvaginal 2D sonography showed a moderately echogenic tumor with some anechoic areas inside the mass of the right ovary. Moreover, transvaginal 2D power Doppler revealed peripheral vascularity with a few central vessels inside the mass. Therefore, the diagnosis of SST of the ovary was also suspected by 2D sonography and power Doppler.

The T2-weighted MRI features of SSTs are "hyperintense cystic or solid heterogeneous components showing an intermediate to high signal intensity within a mass exhibiting a round or oval shape" ${ }^{4,12-14}$ Moreover, dynamic contrast-enhanced imaging reveals early peripheral enhancement with central progression. ${ }^{12-14}$ In our case, T2-weighted MRI revealed that the central portion of the mass had a high signal intensity with a

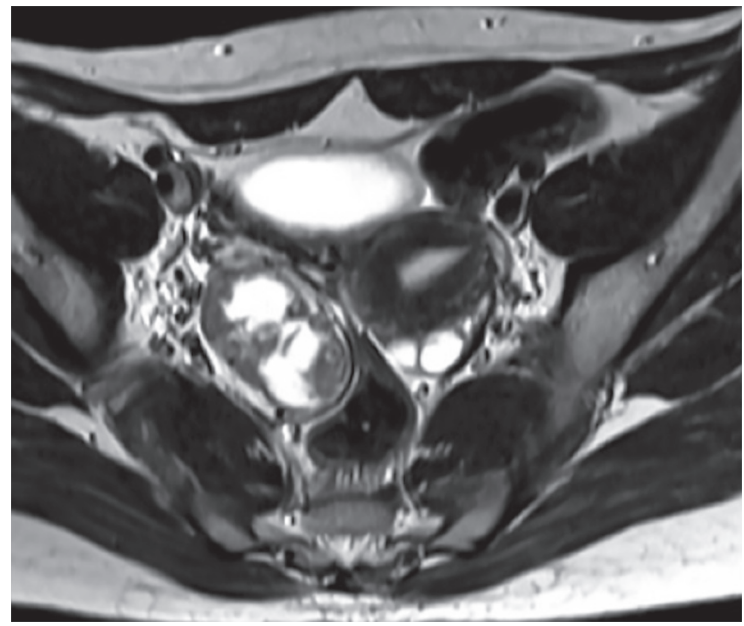

Fig. 4: Axial T2-weighted MRI of a right adnexal mass. T2-weighted MRI reveals that the central portion of the mass has a high signal intensity with a thin, low-intensity peripheral rim 

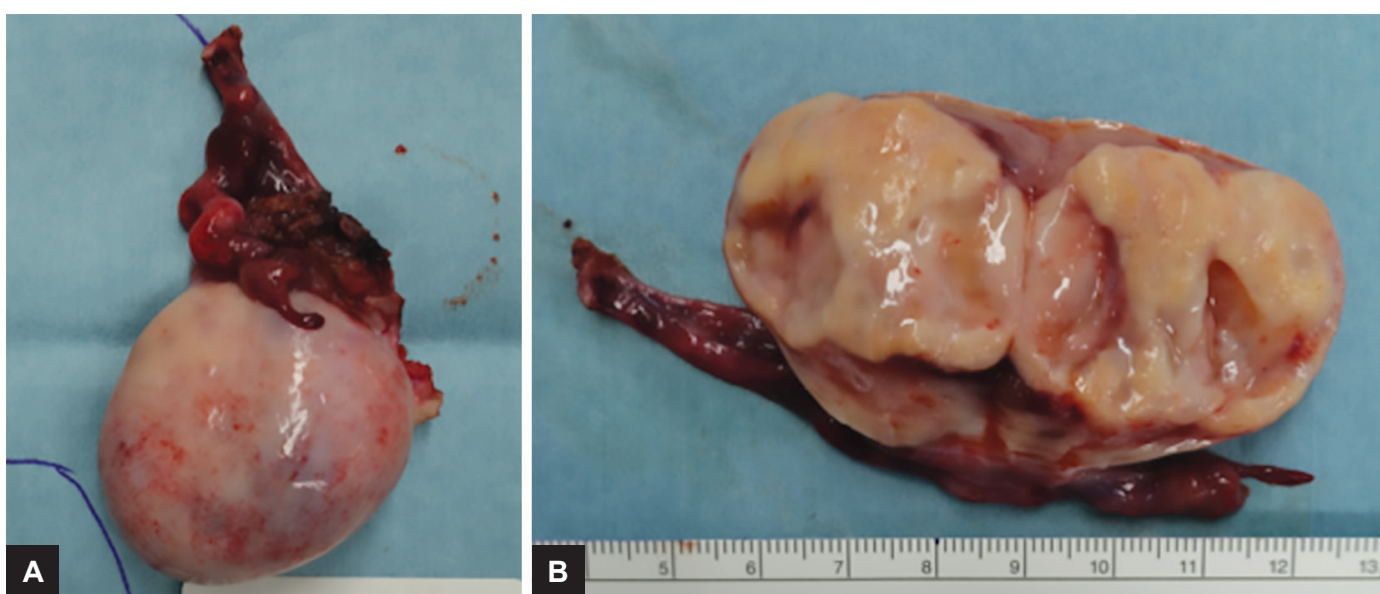

Figs 5A and B: Gross appearance (A) and longitudinally cut view (B) of the right ovary. Macroscopic examination of the surgical specimen shows a capsulated tumor with firm consistency, yellowish nodular, and edema-like parts

thin, low-intensity peripheral rim. Dynamic contrastenhanced MRI demonstrated marked early enhancement of the peripheral portion of the tumor. These findings are consistent with those of SSTs reported previously.

The HDliveFlow silhouette mode provides vitreouslike clarity of blood flow in both the fetal heart and gynecologic disorders and can preserve and present an outline and the borders of blood flow, but the core remains semitransparent..$^{6-9}$ A key advantage of the HDlive silhouette mode is the visualization of anatomical landmarks. ${ }^{15-19}$ "The HDliveFlow silhouette mode with HDlive silhouette mode clearly shows the spatial relationships among the mass of the uterine sarcoma, penetrating abnormal tumor vessels, and surrounding myometrial vessels. ${ }^{\prime 8}$ In the present case, the HDliveFlow silhouette mode with HDlive silhouette mode revealed numerous peripheral vessels with some penetrating vessels and a few cysts inside the SST. In our previous report, HDliveFlow with the HDlive silhouette mode clearly demonstrated a typical vascular-tree-like pattern in the secondary ovarian cancer, whereas complicated abundant branching vessels forming a network with caliber changes (vascular-net pattern) were revealed in the primary ovarian cancer. ${ }^{20}$ Therefore, HDliveFlow silhouette mode with the HDlive silhouette mode may help in differentiating SST from primary and metastatic ovarian cancers. To the best of authors' knowledge, this is the first report on HDliveFlow silhouette mode with HDlive silhouette mode findings of SST of the ovary. The HDliveFlow silhouette mode with HDlive silhouette mode may facilitate the preoperative diagnosis of SST as an adjunctive diagnostic tool along with conventional 2D and power Doppler.

\section{REFERENCES}

1. Chalvardjian A, Scully RE. Sclerosing stromal tumor of the ovary. Cancer 1973 Mar;31(3):664-670.
2. Chang W, Oiseth SJ, Orentlicher R, Agarwal G, Yahr LJ, Cayten CG. Bilateral sclerosing stromal tumor of the ovaries in a premenarchal girl. Gynecol Oncol 2006;101(2):342-345.

3. Kaygusuz EI, Cesur S, Cetiner H, Yavuz H, Koc N. Sclerosing stromal tumor in young women: Clinicopathologic and immunohistochemical spectrum. J Clin Diagn Res 2013 Sep;7(9):1932-1935.

4. Ihara N, Togashi K, Todo G, Nakai A, Kojima N, Ishigaki T, Suginami N, Kinoshita M, Shintaku M. Sclerosing stromal tumor of the ovary: MRI. J Comput Assist Tomogr 1999 Jul;23(4):555-557.

5. Furukawa S, Kanno K, Kojima M, Ohara M, Soeda S, Suzuki S, Watanabe T, Nishiyama H, Honda T, Fujimori K. Sclerosing stromal tumor of the ovary treated with 2-incision total laparoscopic cystectomy. Int J Surg Case Rep 2015;9: 72-74.

6. Ito M, AboEllail MAM, Yamamoto K, Kanenishi K, Tanaka H, Masaoka H, Hata T. HDlive Flow silhouette mode and spatiotemporal image correlation for diagnosing congenital heart disease. Ultrasound Obstet Gynecol 2017 Sep;50(3):411-415.

7. Tenkumo C, Kanenishi K, AboEllail MAM, Yamamoto K, Ishibashi M, Mori N, Tanaka H, Hata T. HDliveFlow silhouette mode for the diagnosis of uterine enhanced myometrial vascularity/arteriovenous malformations. J Med Ultrasonics 2018 Apr;45(2):349-352.

8. Hata T, Kanenishi K, Tanaka T, Ito M, Mori N. HDliveFlow silhouette mode for the diagnosis of uterine sarcoma. Donald School J Ultrasound Obstet Gynecol 2017 Oct-Dec;11(4): 259-260.

9. Hata T, Ito M, Nitta E, Pooh R, Sasahara J, Inamura N. HDlive Flow silhouette mode for diagnosis of ectopia cordis with a left ventricular diverticulum at 15 weeks' gestation. J Ultrasound Med 2018 Mar.

10. Lee MS, Cho HC, Lee YH, Hong SR. Ovarian sclerosing stromal tumors: gray scale and color Doppler sonographic finding. J Ultrasound Med 2001;20(4):413-417.

11. Deval B, Rafil A, Darai E, Hugol D, Buy JN. Sclerosing stromal tumor of the ovary: color Doppler findings. Ultrasound Obstet Gynecol 2003 Nov;22(5):531-534.

12. Matsubayashi R, Matsuno Y, Doi J, Kudo S, Matsuguchi K, Sugimori H. Sclerosing stromal tumor of the ovary: radiologic findings. Eur Radiol 1999 Aug;9(7):1335-1338. 
13. Joja I, Okuno K, Tsunoda M, Takeda Y, Sugita K, Mizutani $Y$, Miyagi Y, Kudo T, Notohara K, Hiraki Y. Sclerosing stromal tumor of the ovary: US, MR, and dynamic MR findings. J Comput Assist Tomogr 2001 Mar-Apr;25(2):201-206.

14. Kim JY, Jung KJ, Chung DS, Kim OD, Lee JH, Youn SK. Sclerosing stromal tumor of the ovary: MR-Pathologic correlation in three cases. Korean J Radiol 2003 Jul-Sep;4(3):194-199.

15. AboEllail MAM, Kanenishi K, Tenkumo C, Mori N, Katayama T, Koyano K, Kusaka T, Hata T. Four-dimensional power Doppler sonography with the HDlive silhouette mode in antenatal diagnosis of a right aortic arch with an aberrant left subclavian artery. J Ultrasound Med 2016 Mar;35(3):661-663.

16. AboEllail MAM, Ishimura M, Sajapala S, Yamamoto K, Tanaka K, Nitta E, Kanenishi K, Hata T. Three-dimensional color/power Doppler sonography and HDlive silhouette mode for diagnosis of molar pregnancy. J Ultrasound Med 2016;35(9):2049-2052.
17. Yamamoto K, AboEllail MAM, Ito M, Mori N, Kanenishi K, Tanaka H, Hata T. HDlive imaging in diagnosis of uterine artery pseudoaneurysm during pregnancy. Ultrasound Obstet Gynecol 2016 Jul;48(1):127-128.

18. Yamamoto K, AboEllail MAM, Ishimura M, Tanaka T, Mori N, Kanenishi K, Hata T. HDlive silhouette inversion mode in diagnosis of complete hydatidiform mole. J Ultrasound Med 2017 Apr;36(4):833-835.

19. Ganjiguur TO, AboEllail MAM, Mori N, Hata T. HDliveFlow with HDlive silhouette mode for diagnosis of persistent right umbilical vein and single umbilical artery. Donald School J Ultrasound Obstet Gynecol 2018 Jan-Mar;12(1):1-3.

20. Sajapala S, AboEllail MAM, Tanaka T, Nitta E, Kanenishi K, Hata T. Three-dimensional power Doppler with silhouette mode for diagnosis of malignant ovarian tumors. Ultrasound Obstet Gynecol 2016 Dec;48(6):806-808. 